\title{
Aberrant synthesis of ATP synthase resulting from a novel deletion in mitochondrial DNA in an African patient with progressive external ophthalmoplegia
}

\author{
Francois H. van der Westhuizen • Joél Smet • \\ Oksana Levanets • Madelein Meissner-Roloff • \\ Roan Louw • Rudy Van Coster • Izelle Smuts
}

Received: 13 July 2009 /Revised: 18 November 2009 / Accepted: 18 November 2009

(C) SSIEM and Springer 2010

\begin{abstract}
A young, adult, African male patient presented with progressive proximal muscle weakness, external ophthalmoplegia and ptosis, as well as cardiac conduction abnormalities resembling Kearns-Sayre syndrome (KSS). Magnetic resonance imaging (MRI) of the brain revealed normal basal ganglia but bilateral well-circumscribed
\end{abstract}

Communicated by: Shamima Rahman

References to electronic databases: Progressive external ophthalmoplegia: OMIM 157640, 609286, 258450, 610131, 609283, 258400. Retinitis pigmentosa: OMIM 600105, 608133, 500004, 612572, 312612, 268025, 268000, 312600, 300389, 180104. KearnsSayre syndrome: OMIM 530000. Pearson marrow-pancreas syndrome: OMIM 557000. ATP:creatine $N$-phosphotransferase (creatine kinase): EC 2.7.3.2. NADH:ubiquinone oxidoreductase (complex I): EC 1.6.5.3. Succinate:ubiquinone oxidoreductase (complex II): EC 1.3.5.1. Ubiquinol:ferricytochrome- $c$ oxidoreductase (complex III): EC 1.10.2.2. Ferrocytochrome- $c$ :oxygen oxidoreductase (complex IV): EC 1.9.3.1. ATP phosphohydrolase (complex V): EC 3.6.1.3. Pyruvate:[dihydrolipoyllysine-residue acetyltransferase]lipoyllysine 2-oxidoreductase (decarboxylating, acceptor-acetylating; pyruvate dehydrogenase complex): EC 1.2.4.1. Acetyl-CoA:oxaloacetate $C$-acetyltransferase [thioester-hydrolysing, (pro-S)carboxymethyl forming] (citrate synthase): EC 2.3.3.1. Deoxynucleoside-triphosphate:DNA deoxynucleotidyltransferase (DNA-directed; DNA polymerase gamma): EC 2.7.7.7.

F. H. van der Westhuizen · O. Levanets · M. Meissner-Roloff • R. Louw

Centre for Human Metabonomics, North-West University, Potchefstroom, South Africa

J. Smet $\cdot$ R. Van Coster

Department of Paediatrics, Division of Paediatric Neurology and Metabolism, Ghent University Hospital,

Ghent, Belgium lesions in the cerebellar peduncles. Enzyme deficiencies in oxidative phosphorylation (OXPHOS) complexes I, $\mathrm{IV}$ and $\mathrm{V}$ was measured in muscle tissue. Blue native polyacrylamide gel electrophoresis (BN-PAGE) confirmed decreased protein content and activity of these complexes and revealed the presence of two catalytically active complex $\mathrm{V}$ sub-complexes. Upon investigation by molecular genetics, the mitochondrial DNA (mtDNA) copy number was found to be elevated and a novel deletion of $3431 \mathrm{bp}$ was found in $80 \%$ of muscle mtDNA between positions 7115 and 10546 , flanked by a 5 bp direct repeat sequence. In addition, it could also be concluded that the absence of mtDNA-encoded ATPase 6 and ATPase 8 genes in this patient clearly resulted in aberrant synthesis of ATP synthase.

\section{Abbreviations}

BN-PAGE blue native polyacrylamide gel electrophoresis

ECG electrocardiogram

EMG electromyogram

MRI magnetic resonance imaging

FLAIR fluid-attenuated inversion-recovery

DWI diffusion-weighted imaging

I. Smuts

Department of Paediatrics,

Steve Biko Academic Hospital,

University of Pretoria,

Pretoria, South Africa

I. Smuts $(\bowtie)$

P.O. Box 32781, Totiusdal 0134, South Africa

e-mail: Izelle.Smuts@up.ac.za 


$\begin{array}{ll}\mathrm{HbA}_{1 \mathrm{C}} & \text { glycohaemoglobin } \\ \text { mtDNA } & \text { mitochondrial DNA } \\ \text { OXPHOS } & \text { oxidative phosphorylation } \\ \text { ROS } & \text { reactive oxygen species }\end{array}$

\section{Introduction}

Mitochondrial disorders are caused by any one of a great number of mutations in nuclear DNA and mitochondrial DNA (mtDNA). Amongst these, mtDNA deletions are often associated with chronic progressive ophthalmoplegia (OMIM 157640, 609286, 258450, 610131, 609283, 258400), Kearns-Sayre syndrome (OMIM 530000), and Pearson marrow-pancreas syndrome (OMIM 557000; Yamashita et al. 2008; Mancuso et al. 2007). These deletions often occur in an area of the mitochondrial genome that encodes the two mitochondrial genes for ATP synthase, ATPase6 and ATPase8 (Mita et al. 1990; Samuels et al. 2004). In our study, clinical, biochemical and molecular genetic findings in an adult African patient with a novel mtDNA deletion in this area of the mitochondrial genome are reported. In addition, the effect of this deletion on the native structure and function of oxidative phosphorylation (OXPHOS) complexes is demonstrated.

\section{Patient and methods}

\section{Patient}

A 22-year-old male patient with progressive proximal muscle weakness, external ophthalmoplegia and ptosis was referred for assessment. The presenting symptom had been ptosis when he was aged 17 years. He had been healthy previously, and there was no family history of any mitochondrial disorder. His initial school performance was satisfactory, and he completed grade 10 . However, at the time of the assessment, the results of the Beery-Buktenica developmental test of visual motor integration correlated with that of an 8-year-old child.

He had asymmetrical but bilateral ptosis, with the left side more affected. He experienced progressive external ophthalmoplegia, and complete ophthalmoplegia was present within 15 months after the initial presentation. Retinitis pigmentosa (OMIM 600105, 608133, 500004, 612572, 312612, 268025, $268000,312600,300389,180104)$ was diagnosed. He had proximal muscle weakness and complained of exercise intolerance. The deep tendon reflexes were diminished. He had dysarthria, a slight tremor and past-pointing, but no ataxia was present initially. Although he did not have ataxia initially, the dysarthria, slight tremor and past pointing were indicative of cerebellar involvement and therefore fulfilled the criteria for Kearns-Sayre syndrome (KSS) (OMIM 530000) as proposed by Moraes et al. (1989).

Gynaecomastia was noted. He had an irregular pulse, but no cardiomegaly or cardiac failure.

\section{Methods}

Ethical aspects

For the specialised investigations described in this report, ethics approval was obtained from the University of Pretoria (number 91/98 and amendments), the North-West University (02M02). Informed consent and assent were obtained from the patient.

\section{Enzyme assays}

A muscle biopsy was taken from the vastus lateralis muscle for further biochemical and molecular genetics analyses. Mitochondrial respiratory chain enzymes complex I (NADH:ubiquinone oxidoreductase, EC 1.6.5.3), complex II (succinate:ubiquinone oxidoreductase, EC 1.3.5.1), complex III (ubiquinol:ferricytochrome-c oxidoreductase, EC 1.10.2.2), complex IV (ferrocytochrome-c:oxygen oxidoreductase, EC 1.9.3.1), combined activity for complex II and III (succinate-cytochrome c reductase) and pyruvate dehydrogenase complex (PDHc, EC 1.2.4.1) were measured in the muscle, essentially as has been described previously (Rahman et al. 1996; Janssen et al. 2007; Chretien et al. 1995). As frozen muscle tissue was used to prepare $600 \mathrm{~g}$ supernatants for assay of respiratory chain enzymes, an assay of complex V (EC 3.6.1.3), which requires freshly isolated mitochondria, was not performed. Citrate synthase (CS; EC 2.3.3.1) activity was determined by the method of Shepherd and Garland (1969), and enzyme activities were expressed as a ratio to CS (as mitochondrial marker enzyme) to compensate for mitochondrial enrichment in the sample (Janssen et al. 2007). Values were compared to reference values obtained from muscle samples from 18 healthy controls undergoing orthopaedic surgery.

Blue native polyacrylamide gel electrophoresis followed by in-gel activity staining

Blue native polyacrylamide gel electrophoresis (BN-PAGE) and in-gel activity staining were performed as has been described previously (Van Coster et al. 2001). Briefly, mitochondria were prepared from the patient together with a control muscle specimen. The mitochondria were solubilised, and $50 \mu \mathrm{g}$ of protein were loaded in duplicate. 
The first set of lanes was used for activity staining of complexes I, III (Meulemans et al. 2007) and IV, and the second set was used for activity staining of complexes II and $\mathrm{V}$.

Western blot analysis of mitochondrial proteins resolved by two-dimensional BN-PAGE

After the first dimension (BN-PAGE), a second denaturing electrophoresis [tricine sodium dodecyl sulphatepolyacrylamide gel electrophoresis (SDS-PAGE)] was performed, for which the BN-PAGE gel was turned $90^{\circ}$ and run in a perpendicular second dimension. In this way, the protein subunits within each OXPHOS complex were separated (Devreese et al. 2002). The twodimensional (2D) gels were electro-blotted onto a nitrocellulose membrane using a tank blotting apparatus from Bio-Rad, as has been described previously (De Vriese et al. 2006). The relative levels of the five OXPHOS complexes were evaluated by immunodetection, using the MS601 MitoProfile ${ }^{\circledR}$ human total OXPHOS complexes detection kit from MitoSciences in a $1 / 1000$ dilution. Detection was done with the enhanced chemiluminescence kit, ECL Plus ${ }^{\mathrm{TM}}$ from GE Healthcare. The signals were captured with a ChemiDoc charge coupled device $(C C D)$ camera and processed with Quantity One ${ }^{\circledR}$ software, both from Bio-Rad.

\section{Molecular genetic analyses}

DNA was extracted from muscle with the NucleoSpin ${ }^{\circledR}$ kit from Macherey-Nagel. In order to investigate the integrity of mtDNA, we performed Southern blot analysis (Selden 1989). For this, $0.1 \mu \mathrm{g}$ to $0.5 \mu \mathrm{g}$ of DNA were digested with $P v u I I$ before electrophoresis and membrane transfer. A probe encompassing the complete mtDNA sequence was prepared by polymerase chain reaction (PCR) (Long PCR Enzyme Mix, Fermentas), using an ND1 gene primer set (forward 5'-GTCTCAGGCTT CAACATCG-3'; reverse 5'-GCATTAGGAATGC CATTGCG-3'). The probe was labelled with alpha 32phosphorus deoxycytidine triphosphate $\left(\alpha-\left[\mathrm{P}^{32}\right] \mathrm{dCTP}\right.$; Izotop) using random prime labelling. After autoradiography, the percentage of deleted DNA was determined by densitometry (GeneTools software, Syngene). In addition to Southern blot analysis, PCR was used to identify and verify the general position of the deletion. The mtDNA primer sets described by Taylor et al. (2001) were used for this purpose.

The total DNA extracted from the patient's muscle and the muscle control DNA samples $(n=18)$ were used to determine the relative mtDNA content. Relative mtDNA content was measured by real-time PCR and calculated using nuclear DNA as a normaliser. The primers and probe for the nuclear reference $\beta$-globin gene were 5'-GTGCACCTGACTCCTGAGGAGA-3' (forward), 5'-CTTGATACCAACCTGCCCAG-3' (reverse) and 5'FAM-AAGGTGAACGTGGATGAAGTTGGTGGTAMRA-3' (probe), synthesised by Metabion International. For mtDNA amplification, an MT-ND2 TaqMan ${ }^{\circledR}$ gene expression assay from Applied Biosystems was used (assay Hs02596874_g1). The PCR was performed with Applied Biosystems's ABI 7300 real-time PCR system in a $25 \mu \mathrm{l}$ volume. Each reaction mixture contained $12.5 \mu 1$ TaqMan $^{\circledR}$ universal PCR master mix, No AmpErase ${ }^{\circledR}$ UNG (2×; Applied Biosystems), $0.5 \mu \mathrm{M}$ forward and reverse primers, $0.2 \mu \mathrm{M}$ probe for $\beta$-globin gene or $1 \times$ dilution of primers/ probe mixture for the MT-ND2 gene, and $10 \mathrm{ng}$ of DNA. The PCR conditions were $10 \mathrm{~min}$ at $95^{\circ} \mathrm{C}$, followed by 40 cycles of denaturation at $95^{\circ} \mathrm{C}$ and annealing/extension at $60^{\circ} \mathrm{C}$ for $1 \mathrm{~min}$, with fluorescence measurement during this step. $C_{T}$ values were calculated with 7300 System Sequence Detection software (version 1.4; Applied Biosystems). All reactions were performed in triplicate. Each assay also included a no-template control, three serial dilution points (in steps of five-fold) of a DNA mixture, and each of the test DNAs (patient and controls). In order to calculate the relative mtDNA content in the patient's DNA, $\mathrm{C}_{\mathrm{T}}$ we exported the values obtained from real-time PCR analyses of the patient and control samples to RESTC software (Relative Expression Software Tool; Pfaffl et al. 2002). PCR efficiency for each primer set was calculated by serial dilution using the REST software tool. The specific mtDNA fragment between positions 6113 and 11727 that contained the deletion was sequenced with an AB1 3130XL genetic analyser (Applied Biosystems) at Inqaba Biotechnical Industries in Pretoria, South Africa. DNA polymerase gamma (EC 2.7.7.7) subunit 1 gene $(P O L G)$ was sequenced, essentially as described by Nguyen et al. (2006).

\section{Results}

The results of the special clinical investigations revealed a right bundle branch block on the electrocardiogram (ECG). The findings of an ultrasound examination of the heart were within normal limits. The findings of an electromyogram (EMG) and nerve conduction studies were within normal limits. The MRI of the brain revealed normal basal ganglia, but bilateral well-circumscribed lesions in the cerebellar peduncles were demonstrated. Low signal intensity on T1-weighted images and high signal intensity on T2-weighted images were observed (Fig. 1). The intensity was mixed on the fluid-attenuated inversion-recovery (FLAIR) images, and restricted diffusion was found on diffusion-weighted imaging (DWI). 




Fig. 1 T2-weighted magnetic resonance image demonstrating the high signal intensity, well-circumscribed lesions in the cerebellar peduncles

Urine analyses revealed the presence of elevated levels of lactic acid, elevated levels of Krebs cycle metabolites, a mild generalised amino-aciduria and glucosuria, but the glycohaemoglobin $\left(\mathrm{HbA}_{1 \mathrm{C}}\right)$ and serum glucose levels were within normal limits. Serum lactate was $4.2 \mathrm{mM}$ and the lactate-topyruvate ratio was 31.3. Blood creatine kinase (EC 2.7.3.2) activity was initially $278 \mathrm{U} / 1$, but it increased over a period of 18 months to 2,083 U/l. Human immunodeficiency virus (HIV) infection was excluded. The patient did not have any proven endocrinological abnormalities.

Muscle histology revealed ragged red fibres and mild lymphocyte infiltration (results not shown). Biochemical analyses of the muscle biopsy confirmed the suggestion of a mitochondrial disorder and were informative as to the deficiency that existed. From the data from respiratory chain and PDHc enzyme activity, which are summarised in Table 1, it was concluded that there was a combined deficiency of complexes I, II+III, and IV. BN-PAGE analysis of muscle provided additional information on the deficiency (Fig. 2). The OXPHOS complexes were already visible in the gel without additional staining, owing to the coomassie dye, which induced a charge shift of the proteins and which thus revealed the protein content of the complexes (Smet et al. 2005). By comparing the intensities of the OXPHOS protein bands between the lane loaded with the patient's muscle mitochondria and a control lane, we noticed decreased protein content of complexes I and IV and the V holo-complex (Fig. 2, left side of panel A). Consequently, following in-gel activity staining, decreased catalytic activity of those complexes could be demonstrated. The enzyme activities of complexes II and III seemed comparable. Two catalytically active complex V subcomplexes in the patient's sample were observed (Fig. 2, right side of panel A).

Using western blotting following 2D BN/SDS-PAGE, we observed a reduced signal for the complex I subunit (NDUFB8-20 kDa) and the complex IV subunit (COX II, $26 \mathrm{kDa}$ ) in the patient. Three different bands originating from the complex $\mathrm{V}$ alpha subunit were also detected. The signal intensities of the complex II subunit (Ip, $30 \mathrm{kDa}$ ) and the complex III subunit (core 2, $47 \mathrm{kDa}$ ) were, however, comparable between patient and control samples (Fig. 2, panel B).

Initial analysis of mtDNA structure (Fig. 3a, b) clearly revealed a deletion of $\sim 3.4 \mathrm{kbp}$, which was present in $80 \%$ of the mtDNA copies of the patient's muscle biopsy according to the densitometry of various DNA dilutions. Further investigations revealed that the deletion occurred in an area between nucleotide positions $\sim 6000$ and $\sim 12000$ (Fig. 3c, d). It was also observed that the mtDNA copy number was notably higher $(219 \%)$ than the average of that of controls $(n=8)$. In addition, no pathogenic mutations were detected in the POLG gene. From sequencing data, the position of the deletion on mtDNA was determined to be present between positions 7115 and 10546, as shown in Fig. 4. This 3,431 bp deletion included five transfer RNA (tRNA) genes, two genes of complex I (ND4L and ND3), all three genes of complex IV (CO I-III) and both mitochondrially encoded genes of complex $\mathrm{V}$ (ATPase6 and ATPase8). The deletion occurred immediately after, and on the $3^{\prime}$ end also included, the sequence ACACC.

Table 1 Respiratory chain and PDHc enzyme activities in the patient's muscle. Activities are expressed against several reference enzymes as shown: $\mathrm{mU}, \mathrm{nmol} / \mathrm{min}$; UCS, $\mu \mathrm{mol} / \mathrm{min}$ citrate synthase activity; PDHc, pyruvate dehydrogenase complex

\begin{tabular}{|c|c|c|c|c|c|c|c|c|c|c|c|c|c|c|c|}
\hline \multirow[t]{2}{*}{ Sample } & \multicolumn{3}{|c|}{ Complex I } & \multicolumn{2}{|c|}{ Complex II } & \multicolumn{3}{|c|}{ Complex III } & \multicolumn{3}{|c|}{ Complex II+III } & \multicolumn{2}{|c|}{ Complex IV } & \multicolumn{2}{|l|}{ PDHc } \\
\hline & $\mathrm{mU} / \mathrm{UCS}$ & $\mathrm{CI} / \mathrm{CII}$ & $\mathrm{CI} / \mathrm{CIV}$ & $\mathrm{mU} / \mathrm{UCS}$ & $\mathrm{CII} / \mathrm{CIV}$ & $\mathrm{mU} / \mathrm{UCS}$ & $\mathrm{CIII} / \mathrm{CII}$ & $\mathrm{CIII} / \mathrm{CIV}$ & $\mathrm{mU} / \mathrm{UCS}$ & $\mathrm{CII}+\mathrm{III} / \mathrm{CII}$ & $\mathrm{CII}+\mathrm{III} / \mathrm{CIV}$ & $\mathrm{mU} / \mathrm{UCS}$ & $\mathrm{CIV} / \mathrm{CII}$ & $\mathrm{mU} / \mathrm{mg}$ & $\mathrm{mU} / \mathrm{UCS}$ \\
\hline Patient & $150^{\mathrm{a}}$ & $1.9^{\mathrm{a}}$ & 12.0 & 79.2 & 6.3 & 392 & 4.95 & 31.2 & $75^{\mathrm{a}}$ & $0.94^{\mathrm{a}}$ & 5.94 & $13^{\mathrm{a}}$ & $0.2^{\mathrm{a}}$ & 42.6 & 101 \\
\hline $\begin{array}{l}\text { Control range } \\
(n=18)\end{array}$ & $219-372$ & $1.9-4.5$ & $2.1-7.1$ & $72.8-149$ & $0.78-2.1$ & $327-787$ & $2.97-9.32$ & $5.04-14.5$ & $117-234$ & $1.14-2.2$ & $1.28-3.67$ & $43.1-124$ & $0.5-1.3$ & $4.0-96.5$ & $7.8-104$ \\
\hline
\end{tabular}

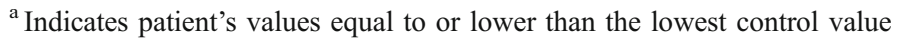



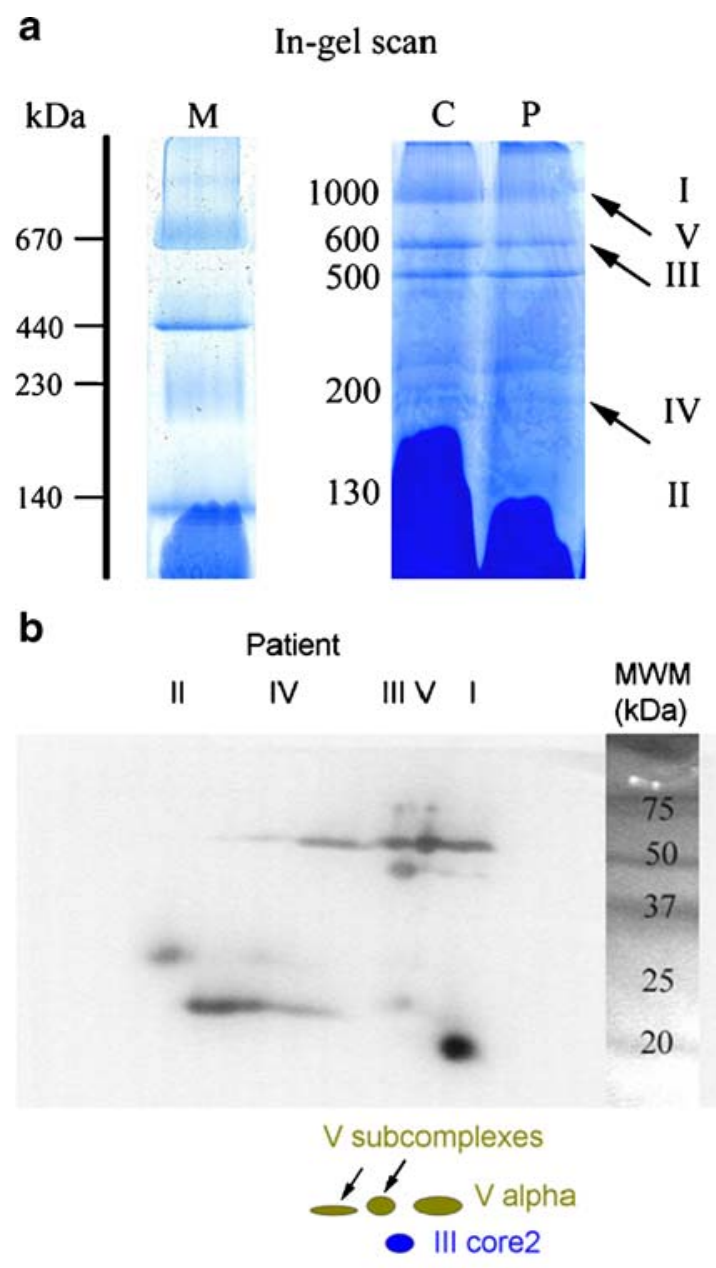

Fig. 2 BN-PAGE and 2D BN-PAGE western blotting. Panel A. Legend: (M) native molecular weight marker, $(\mathrm{C})$ control muscle, $(\mathrm{P})$ patient muscle. Left side: scan of the gel following BN-PAGE; arrows mark decreased amounts of OXPHOS complex proteins (I, IV and V) in the patient compared to those in the control sample. Right side: ingel activity of the patient's muscle, indicating decreased activity of complexes I and IV, whilst the activities of complexes III and II are comparable to those of the control sample. Note the presence of catalytically active complex $\mathrm{V}$ sub-complexes, which are suggestive of disturbed intra-mitochondrial protein synthesis. Panel B. Immunos-

\section{Discussion}

A patient of African origin with a novel deletion in his mtDNA has been described. The patient presented with external ophthalmoplegia, ptosis and retinitis pigmentosa resembling KSS. The MRI findings comprising normal basal ganglia and bilateral well-circumscribed lesions in the cerebellar peduncles (Fig. 1) might not comply entirely with the classical description of MRI findings in KSS, but there is limited correlation between the MRI findings and

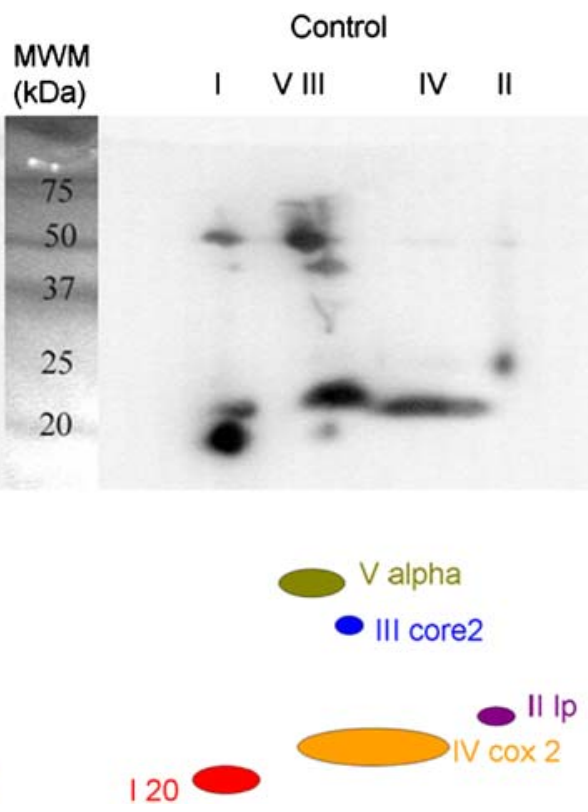

\section{In-gel activity staining}

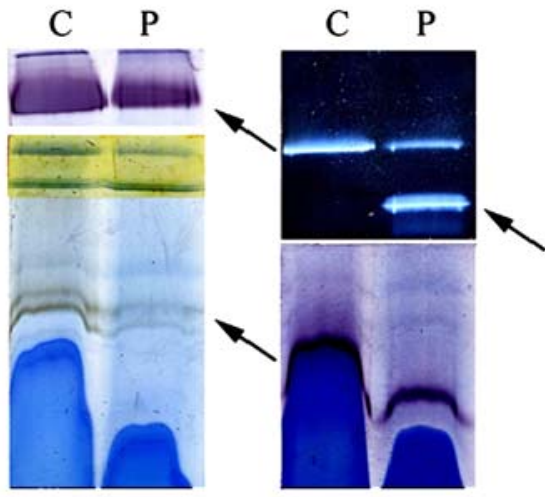

Control

taining of OXPHOS proteins from patient and control samples following 2D BN-PAGE, using specific antibodies against subunits of the five OXPHOS complexes. MWM: molecular weight marker. The signals from the complex I subunit (NDUFB8, $20 \mathrm{kDa}$ ) and the COX II subunit are reduced in the patient in comparison with those of the control. The signals of the other OXPHOS subunits, complex III core 2 and complex II Ip, are comparable to those of the control. Notice the presence of two additional signals from the complex $\mathrm{V}$ alpha subunit, indicating the presence of two sub-complexes of complex V

the neurological deficits in KSS (Chu et al. 1999; LermanSagie et al. 2005). Bilateral lesions of high signal intensity on T2-weighted images of the globus pallidus and subcortical cerebral white matter are characteristic of KSS (Lerman-Sagie et al. 2005). Other common MRI findings include cerebral and cerebellar atrophy, bilateral lesions of high signal intensity in the thalamus, substantia nigra and brain stem (Leutner et al. 1994; Wray et al. 1995; Saneto et al. 2008). On the other hand, according to Barragan-Campos et al. (2005), basal ganglia involvement might not always be 


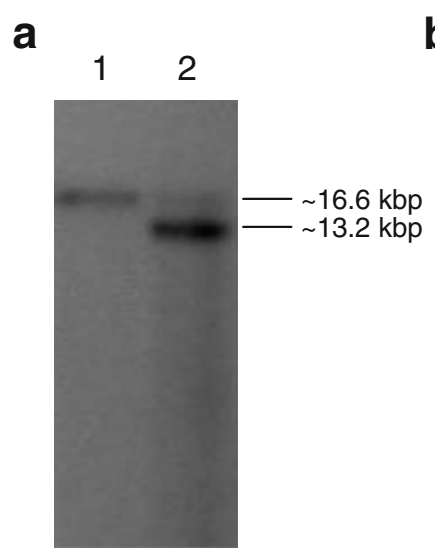

b

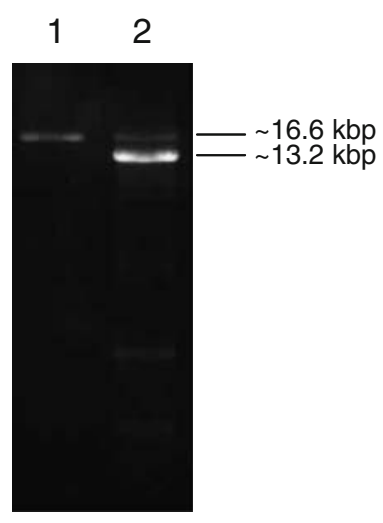

C

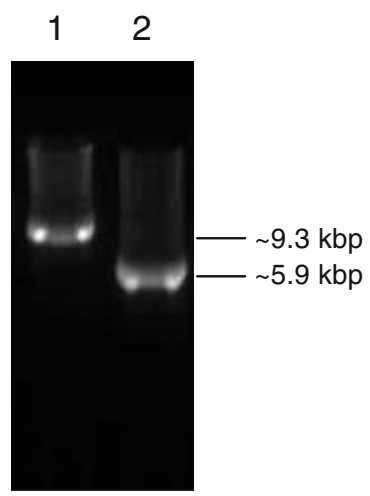

d

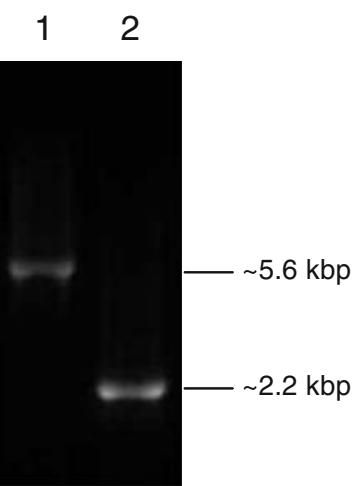

Fig. 3 Southern blot and PCR analysis of mtDNA. DNA of a healthy control (1) and the patient (2) was pre-treated with $P v u I I$ and subjected to Southern blot analysis (a). PCR and ethidium bromide-containing gel electrophoresis using several primers were used to identify the region of deletion $(b-d)$. The primers used were complementary to the following positions on the mtDNA genome: 37-58 (forward) and 16537-16558 (reverse), which amplified the complete mtDNA genome (b); 6113-6133 (forward) and 15431-15409 (reverse) in (c); 6113-6133 (forward) and 11748-11727 (reverse) in (d)

present. The white matter lesions can affect both the deep cerebral and cerebellar white matter (Lerman-Sagie et al. 2005). Heidenreich et al. (2006) described involvement of the cerebellar peduncles in their study of patients with chronic progressive external ophthalmoplegia (CPEO), including a patient with KSS. Bianchi et al. (2007) classify the MRI changes found in KSS as the syndromic type II pattern. The rest of the spectrum constitutes the type I pattern, which includes the more non-specific changes, and type III, the more leukodystrophy-like pattern.

A combined deficiency of OXPHOS complexes I, II+III, and IV was identified from the initial enzyme analyses. From our initial diagnostic analyses, which included a very simple but valuable PCR analysis to screen for mtDNA macro-structural changes, an mtDNA deletion was clearly present in this case, which required further investigation. The additional results obtained following BN-PAGE revealed reduced protein content and activities of complex I, IV and V. These findings were in agreement with the

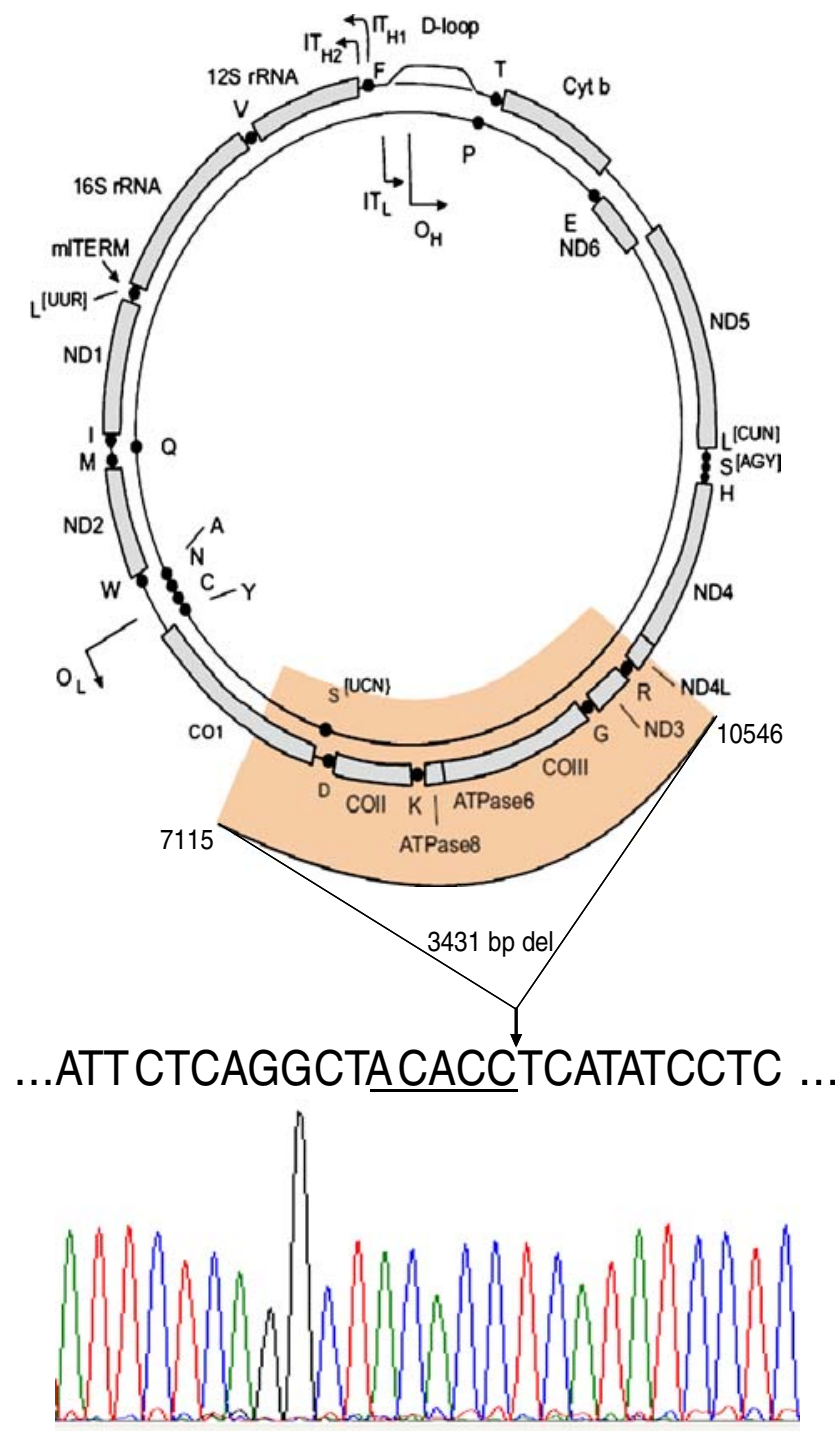

Fig. 4 Position of deletion in the patient's mtDNA. An electropherogram on the bottom indicates the position of the 3431 bp deletion, with the flanking repeat sequence underlined (the repeat sequence occurs at the $3^{\prime}$ end of the deletion as well). The position of the deletion on mtDNA and the genes involved are highlighted in the top part of the figure (adapted from Taanman 1999). Nucleotide positions are according to the Revised Cambridge Reference Sequence (GenBank J01415.2)

genes deleted from mtDNA in this patient. Both the protein content and activity of complex III, which, apart from absent tRNA genes, is not affected by the deletion, as well as nuclear-encoded complex II, were comparable to those of the control sample. Additionally, notable aspects of complex V synthesis and activity were demonstrated in the patient's sample. It was observed that the activity of complex $\mathrm{V}$ was reduced in the patient but that a catalytically active sub-complex of complex $\mathrm{V}$ existed. Some activity remained in the holo-complex, which might be attributed to the $20 \%$ wild-type mtDNA present in the patient. This finding points to disturbed intra-mitochondrial 
protein synthesis, which can be attributed to the absence of the two mtDNA genes for complex V, ATPase6 and ATPase8 (Carrozzo et al. 2006; Smet et al. 2009).

Several characteristics of the deletion should be noted. The position of this relatively small deletion $(3,431 \mathrm{bp})$, present in $80 \%$ of mtDNA copies, has not previously been reported in the literature. The deletion break points are flanked precisely by direct repeats, which identify it as a class I deletion according to the classification by Mita et al. (1990). Deletions of this class are the most common and occur in $\sim 60 \%$ of all known cases (Samuels et al. 2004). The reported deletion is located in the mtDNA region, where a high deletion frequency occurs. The $5^{\prime}$ end of the deletion (7115) falls within the $5^{\prime}$-end distribution range (5835 to 12112) that is common for most deletions, as reported by Mita et al. (1990). It also falls within the distribution range of around $8 \mathrm{kbp}$ to $9 \mathrm{kbp}$ (7832 bp to $8653 \mathrm{bp}$ median values) for $5^{\prime}$ ends of mtDNA deletions, as reported by Samuels et al. (2004). However, the $3^{\prime}$ end of the reported deletion (10546) is not situated within the common $3^{\prime}$-end distribution range, which is mostly found in the region between 12661 and 15945 . Samuels et al. (2004) reported that the distribution of 3'end deletion has two peaks, which is different from the unimodular distribution for $5^{\prime}$ ends, consisting of a broad peak, centred on the median values of 13958 to 14643 , and a sharp peak, at position 16000 to 16100 .

The associated increased mtDNA replication observed is known to occur in patients with mtDNA deletions (Bai and Wong 2005). Although increased oxidative stress or oxidative damage was not measured in the tissue, mtDNA overexpression may occur through the reactive oxygen species (ROS)-mediated induction of mtDNA transcription and replication factors (Miranda et al. 1999; Lee and Wei 2005).

Acknowledgements The authors would like to thank the Medical Research Council of South Africa for financial support.

\section{References}

Bai RK, Wong LJC (2005) Simultaneous detection and quantification of mitochondrial DNA deletion(s), depletion, and overreplication in patients with mitochondrial disease. J Mol Diagn 7:613-622

Barragan-Campos HM, Valee J-N, Lo D et al (2005) Brain magnetic resonance imaging findings in patients with mitochondrial cytopathies. Arch Neurol 62:737-742

Bianchi MC, Sgandurra G, Tosetti M et al (2007) Brain magnetic resonance in the diagnostic evaluation of mitochondrial encephalopathies. Biosci Rep 27:69-85

Carrozzo R, Wittig I, Santorelli FM et al (2006) Subcomplexes of human ATP synthase mark mitochondrial biosynthesis disorders. Ann Neurol 59:265-275

Chretien D, Pourrier M, Bourgeron T et al (1995) An improved spectrophotometric assay of pyruvate dehydrogenase in lactate dehydrogenase contaminated mitochondrial preparations from human skeletal muscle. Clin Chim Acta 240:129-136

Chu BC, Terae S, Takahashi C et al (1999) MRI of the brain in the Kearns-Sayre syndrome: report of four cases and a review. Neuroradiology 41:759-764

De Vriese AS, Van Coster R, Smet J et al (2006) Linezolid-induced inhibition of mitochondrial protein synthesis. Clin Infect Dis 42:1111-1117

Devreese B, Vanrobaeys F, Smet J, Van Beeumen J, Van Coster R (2002) Mass spectrometric identification of mitochondrial oxidative phosphorylation subunits separated by two-dimensional blue-native polyacrylamide gel electrophoresis. Electrophoresis $23: 2525-2533$

Heidenreich JO, Klopstock T, Schrimer T et al (2006) Chronic progressive external ophthalmoplegia: MR spectroscopy and MR diffusion studies in the brain. AJR Am J Roentgenol 187:820-824

Janssen AJ, Trijbels FJ, Sengers RC et al (2007) Spectrophotometric assay for complex I of the respiratory chain in tissue samples and cultured fibroblasts. Clin Chem 53:729-734

Lee HC, Wei YH (2005) Mitochondrial biogenesis and mitochondrial DNA maintenance of mammalian cells under oxidative stress. Int J Biochem Cell Biol 37:822-834

Lerman-Sagie T, Leshinsky-Silver E, Watemberg N et al (2005) White matter involvement in mitochondrial diseases. Mol Genet Metab $84: 127-136$

Leutner C, Layer G, Zierz S et al (1994) Cerebral MR in ophthalmoplegia plus. AJNR Am J Neuroradiol 15:681-687

Mancuso M, Filosto M, Choub A et al (2007) Mitochondrial DNArelated disorders. Biosci Rep 27:31-37

Meulemans A, De Paepe B, De Bleecker J et al (2007) Two novel mitochondrial DNA mutations in muscle tissue of a patient with limb-girdle myopathy. Arch Neurol 64:1339-1343

Miranda S, Foncea R, Guerrero J, Leighton F (1999) Oxidative stress and upregulation of mitochondrial biogenesis genes in mitochondrial DNA-depleted HeLa cells. Biochem Biophys Res Commun 258:44-49

Mita S, Rizzuto R, Moraes CT et al (1990) Recombination via flanking direct repeats is a major cause of large-scale deletions of human mitochondrial DNA. Nucl Acids Res 18:561-567

Moraes CT, DiMauro S, Zeviani M et al (1989) Mitochondrial DNA deletions in progressive external ophthalmoplegia and KearnsSayre syndrome. N Engl J Med 320:1293-1299

Nguyen KV, Sharief FS, Chan SS et al (2006) Molecular diagnosis of Alpers syndrome. J Hepatol 45:108-116

Pfaffl MW, Horgan GW, Dempfle L (2002) Relative expression software tool (RESTC) for group-wise comparison and statistical analysis of relative expression results in real-time PCR. Nucl Acids Res 30:2-10

Rahman S, Blok RB, Dahl HH et al (1996) Leigh syndrome: clinical features and biochemical and DNA abnormalities. Ann Neurol 39:343-351

Samuels DC, Schon EA, Chinnery PF (2004) Two direct repeats cause most human mtDNA deletions. Trends Genet 20:393-398

Saneto RP, Friedman SD, Shaw DWW (2008) Neuroimaging of mitochondrial disease. Mitochondrion 8:396-413

Selden RF (1989) Analysis of DNA sequences by blotting and hybridization. In: Ausubel FM, Brent R, Kingston RE, Moore DD, Seidman JG, Smith JA, Struhl K (eds) Current protocols of molecular biology. Wiley Interscience, New York, pp 2.9.12.9 .10

Shepherd D, Garland PB (1969) The kinetic properties of citrate synthase from rat liver mitochondria. Biochem J 114:597-610

Smet J, Devreese B, van Beeumen J, Van Coster R (2005) Nondenaturing polyacrylamide gel electrophoresis as a method for studying protein interactions: applications in the analysis of mitochondrial OXPHOS complexes. In: Celis JE (ed) Cell 
biology: a laboratory handbook. Academic, San Diego, pp 259-264

Smet J, Seneca S, De Paepe B, Meulemans A, Verhelst H, Leroy J, De Meirleir L, Lissens W, Van Coster R (2009) Subcomplexes of mitochondrial complex $\mathrm{V}$ reveal mutations in mtDNA. Electrophoresis 30:3565-3572

Taanman J-W (1999) The mitochondrial genome: structure, transcription, translation and replication. Biochem Biophys Acta 1410:102-123

Taylor RW, Taylor GA, Durham SE, Turnbull DM (2001) The determination of complete human mitochondrial DNA sequences in single cells: implications for the study of somatic mitochondrial DNA point mutations. Nucl Acids Res 29:E74

Van Coster R, Smet J, George E et al (2001) Blue native polyacrylamide gel electrophoresis: a powerful tool in diagnosis of oxidative phosphorylation defects. Pediatr Res 50:658-665

Wray SH, Provenzale JM, Johns DR et al (1995) MR of the brain in mitochondrial myopathy. AJNR Am J Neuroradiol 16:1167-1173

Yamashita S, Nishino I, Nonaka I, Goto Y (2008) Genotype and phenotype analyses in 136 patients with single large-scale mitochondrial DNA deletions. J Hum Genet 53:598-606 